CIC. Cuadernos de Información y Comunicación

ISSN: $1135-7991$

https://dx.doi.org/10.5209/ciyc.76022

\title{
Alcácer Guirao, Rafael (2020) La libertad del odio. Discurso intolerante u protección penal de minorías. Madrid: Marcial Pons, 273 pp.
}

No corren buenos tiempos para la libertad de expresión es España. En los últimos años hemos visto como raperos, titiriteros, habitantes de las redes sociales o bromistas, pero también medios de comunicación y periodistas, eran vapuleados a nivel social y llevados frente a los tribunales con diferentes consecuencias. Tampoco corren buenos tiempos para el debate informado y reflexivo sobre la relación entre discurso político, libertades públicas y regulaciones legales. La ambición de aniquilar el discurso ajeno, calificándolo de discurso de odio y prohibiéndolo, recorre las filas de todas las posiciones políticas. En este clima, este libro de Rafael Alcácer es enormemente pertinente.

La libertad de expresión es un campo en el que confluyen los intereses tanto de los juristas como de los periodistas y de los académicos del campo de la comunicación. Es un cruce de caminos que debería funcionar a la antigua, como un espacio de encuentro, confluencia y mercadeo, pero en nuestro mundo contemporáneo se organiza de forma opuesta como un lugar en que emboscar al contrincante y aniquilar al enemigo. Necesitamos, más allá de las leyes, un debate democrático, una conversación que parta del disenso y del reconocimiento de la validez de las posiciones del oponente. Un debate en la esfera pública, informado por los medios, antes de que sean los tribunales los que, a golpe de sentencia, organicen nuestra vida en común.

El libro de Alcácer ofrece un buen arsenal de razones para sostener muy diversas posiciones sobre cómo deber regularse en una democracia el discurso del odio. ¿Podemos, con el objetivo de asegurar la tolerancia, aniquilar el discurso intolerante? Para establecer una discusión informada, el libro contrasta las posiciones que el derecho estadounidense y el europeo han establecido al respecto, lo que le lleva a hacer un recorrido por cómo el liberalismo, el republicanismo y el multiculturalismo estructuran la coexistencia de los intereses de la comunidad política, los grupos identitarios y los individuos. Porque la discusión sobre el discurso del odio descansa en una cuestión anterior ¿Tienen derechos los grupos, o estos son de los individuos en tanto sujetos del cuerpo político? Para algunos puede sonar a discusión bizantina, pero pueden darse una vuelta por Cataluña para conectar esta discusión con la realidad contemporánea.

Discutir sobre el discurso del odio es poner encima de la mesa la cuestión de las identidades grupales y su papel en la política y en la vida social. Los partidarios de una visión multiculturalista de la sociedad defienden que la agresión a la identidad de un grupo es una agresión a cada uno de sus miembros, y que por ello es obligación del Estado evitar este tipo de discurso, incluso recurriendo a la justicia penal. Frente a estas posiciones, liberales y republicanistas apelan a una democracia deliberativa que hace suyas las ideas de Rawls: suprimir la expresión subversiva es suprimir la 
discusión de los argumentos, lo que equivale a restringir el uso libre de nuestra razón, que está en la base de la democracia.

El reciente encarcelamiento del rapero Pablo Hasél añade una capa de complejidad al problema: ¿cualquier grupo identitario merece de la misma protección? Los tribunales europeos han insistido en que las instituciones (la Casa Real, pero también la policía) deben asumir una exposición más intensa a la crítica y que por tanto no requieren de protección reforzada alguna como otorga el ordenamiento jurídico español.

Más allá del análisis del entramado jurídico y sus justificaciones, este es un libro que intenta dar respuesta a la cuestiones esenciales que organizan nuestra vida en común, confrontando la gran pregunta que se ha planteado siempre la ciencia social: cómo es posible la existencia de la sociedad. ¿Qué papel debe jugar la ley en la regulación de la comunicación que hace posible que tomemos decisiones en común? Además, con una prosa que aúna lo emocional con lo analítico, extraordinariamente clara incluso para los no familiarizados con el derecho, el libro apela a cuestiones que interesan sin duda a la comunidad académica de la comunicación.

No he podido evitar sentirme constantemente apelado cada una de las veces que el concepto de discurso aparece en el libro. La democracia, tal y como la reconstruye Alcácer a través de las opiniones de los juristas y de la filosofía política, es básicamente un espacio de deliberación, un ágora en la que los ciudadanos se encuentran para confrontar sus perspectivas. El libro es un elogio del disenso y de su papel fundamental en la vida en común: el fin de ese mundo, dijo Hannah Arendt, llega cuando se presenta únicamente una perspectiva. El desacuerdo, y no el consenso, es el elemento fundamental de una democracia. Por tanto, es necesario dar voz a todas las perspectivas, incluso a aquellas que discuten a la propia democracia. Y combatirlas no mediante la ley o la violencia, sino a través del propio discurso.

No existe, en democracia, un derecho a no ser ofendido: el debate público implica aceptar lo desagradable y lo soez en nombre de valores superiores. Pero, como el libro recuerda a menudo, asumir esta máxima no implica desatender a la desigualdad constitutiva del espacio público: los gobiernos tienen en su mano instrumentos diversos para garantizar la igualdad comunicativa que reclamaba Todorov. Este punto reclama de nuevo atención a la complejidad del debate sobre la libre expresión: no se trata solo de regular penalmente lo que se dice, sino también de crear un marco comunicativo en el que las minorías puedan hacer oír su voz y confrontar los ataques. No se trata, pues, de dar una respuesta penal a los conflictos sobre libertad de expresión, sino de establecer políticas que aseguren un ecosistema comunicativo plural y representativo de la complejidad de nuestras sociedades.

Este ecosistema plural requiere de ciudadanos bien equipados a nivel comunicativo. Requiere de un tono moral radicalmente diferente al actual en el que el disenso, la subversión y la ofensa sean entendidos como elementos constitutivos del debate político y no una amenaza a este. El disenso que Alcácer defiende, siguiendo a Cass Sunstein, recuerda en buena manera a la duda que Peirce reivindicaba como base de la creencia: la duda genera una inquietud que sólo llega a calmarse cuando, a través de la indagación compartida con la comunidad, llegamos a establecer una creencia que es sostenida en el tiempo como un hábito. El discurso es la forma que tenemos de dar sentido y organizar nuestra vida en común: es un proceso de semiosis en el que la introducción de perspectivas disruptivas juega un papel fundamental. 
La reivindicación de la tolerante tradición jurídica estadounidense que recorre el libro, sobre todo a través de las opiniones de Louis Brandeis y Oliver Wendell Holmes desde el Tribunal Supremo del primer tercio del siglo XX, apelan a la teoría de la pendiente resbaladiza (slippery slope): admitir una cierta restricción legal de la libertad de expresión abre siempre la puerta a más restricciones futuras. Situarnos frente al discurso del odio implica afrontar las complejidades de la vida en común y la fragilidad de todo sistema democrático, asumiendo, en palabras de Brandeis, que el remedio frente al extremismo debe ser el discurso y no la imposición del silencio

Héctor Fouce hfoucero@ucm.es 